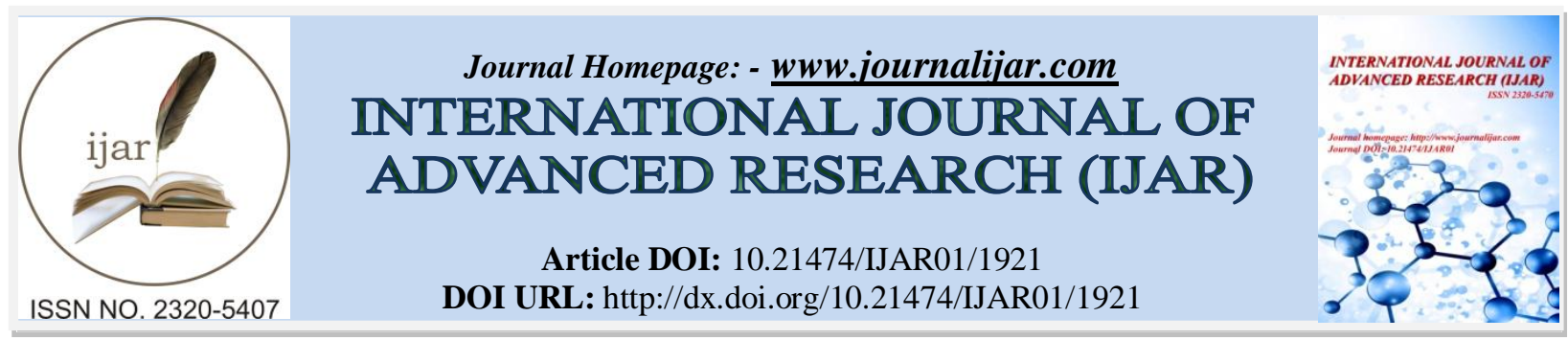

RESEARCH ARTICLE

\title{
EFFECT OF IN UTERO CADMIUM AND/OR ZINC EXPOSURE ON OCCURRENCE OF SQUELETAL ABNORMALITIES.
}

Sana Boughammoura, Marouane Chemek, Safa Ben Mimouna and Imed Messaoudi* . LR11ES41: Genetique, Biodiversite et Valorisation des Bioressources. Institut de Biotechnologie, Universite de Monastir, 5000 Monastir, Tunisia.

\section{Manuscript Info}

Manuscript History

Received: 12 August 2016

Final Accepted: 16 September 2016

Published: October 2016

Key words:-

cadmium, zinc, prenatal skeleton, toxicity, pregnancy.

\section{Abstract}

Cadmium (Cd) is widely dispersed heavy metal, of current environmental concern. It is well known that many toxic effects of $\mathrm{Cd}$ result from interactions with essential elements, including zinc (Zn) which is necessary for growth, development and maintenance of bone health. This study explored the effect of in utero $\mathrm{Cd}$ exposure on the induction of skeletal deformities and the protective effect of $\mathrm{Zn}$ against $\mathrm{Cd}$ toxicity. For this purpose, female rats received either tap water, $\mathrm{Cd}, \mathrm{Zn}$ or $\mathrm{Cd}+\mathrm{Zn}$ in their drinking water during gestation and skeletal deformities were indentified and quantified in their fetuses removed at the $20^{\text {th }}$ day of pregnancy (GD20). Numerous skeletal defects were documented during examination of the stained fetal specimens. The identified malformations were localized at the axial skeleton level in different regions (skull, sternum, thoracic region, lumbar region and phalange) and the highest incidence occurred after exposure to $\mathrm{Cd}$. Compared to $\mathrm{Cd}$ group, co-treatment with $\mathrm{Cd}$ and $\mathrm{Zn}$ has no significant effect on body and femur weight but a significant reduction of the occurrence of skeletal abnormalities was observed. Our results highlight the protective role of $\mathrm{Zn}$ against $\mathrm{Cd}$-induced skeletal abnormalities and indicate that the toxic effect of $\mathrm{Cd}$ can be mediated, at least in part, by the perturbation of $\mathrm{Zn}$ metabolism.

Copy Right, IJAR, 2016,. All rights reserved.

\section{Introduction:-}

Cadmium $(\mathrm{Cd})$ is a toxic substance that is widely distributed in the environment and has a long biological half-life in organs. The kidneys, liver, bones, and respiratory and cardiovascular systems are the most important target organs for Cd toxicity (WHO, 1992). Cd exposure can cause itai-itai disease, kidney tubular dysfunction, cancer, and bone damage (Om et al., 2002; Itokawa et al., 1978). This metal also has embryonary and fetal toxicity affecting the development of pre-and post-implantation rodent embryos (Thompson and Bannigan 2008). However, little information on the effects of Cd exposure in early life has been shown (Thompson and Bannigan 2008). The effects of $\mathrm{Cd}$ on rat fetuses reported comprise deformities in brain (hydrocephalus), eyes (anophthalmia, microphthalmia), gastroschisis, umbilical hernia (Samarawickrama and Webb 1979), urogenital abnormalities and cleft palate (Holt and Webb 1987). Several investigations confirmed its transport across the placenta and accumulation in fetus (Kippler et al. 2010; Nakamura et al. 2012).

Corresponding Author:- Imed Messaoudi.

Address:- LR11ES41: Genetique, Biodiversite et Valorisation des Bioressources. Institut de

Biotechnologie, Universite de Monastir, 5000 Monastir, Tunisia. 
The exact mechanism of Cd-induced teratogenicity is not known. However, there is evidence that this action of Cd may be mediated by alterations in Zn metabolism (Sorell and Graziano, 1990; Suzuki K.T. et al., 1990). Zn is an essential nutrient for life required for many aspects of fetal growth and plays important roles in both prenatal and postnatal development, it represent a cofactor of many essential enzymes such as alkaline phosphatase (ALP) and stimulate gene transcription by increasing the expression of several osteoblastic markers such as pro-collagen type I, osteocalcin and osteopontin (ref). The stimulation mechanisms of bone formation by $\mathrm{Zn}$ have not yet been elucidated as the number of proteins and enzymes containing $\mathrm{Zn}$ is important in bone cells (Tang et al., 2006). Decreased $\mathrm{Zn}$ concentrations in fetal tissue, accompanied by reduction in the activities of $\mathrm{Zn}$ metalloenzymes in both maternal and their fetuses and is associated with skeletal abnormalities in bone growth and mineralization (Nishi, 1996; Okano, 1996).

Although, $\mathrm{Cd}$ and $\mathrm{Zn}$ interactions during early life have been reported in some studies, many questions remain to be answered with respect to the consequence of these interactions on the skeletal formation and their involvement in Cd-induced skeletal abnormalities. Thus, this study explored the effect of in utero $\mathrm{Cd}$ exposure on the induction of skeletal deformities and the protective effect of $\mathrm{Zn}$ against $\mathrm{Cd}$ toxicity.

\section{Materials and Methods:-}

\section{Animals and experimental design:-}

Male and female Wistar rats weighing 150-230 g were used in this study. The animals were housed in individual stainless steel cages at $23 \pm 1{ }^{\circ} \mathrm{C}$ and exposed to 12-h light-dark cycle. They had access to a standard rodent laboratory diet (SICO, Sfax, Tunisia) and drinking water ad libitum. The animals were housed according to the EEC 609/86 Directives regulating the welfare of experimental animals. After acclimatization, one fertile male rat was placed into each cage with a female overnight. Pregnancy was detected by the presence of spermatozoa in the vaginal smear next morning and this was considered the day zero of gestation (GD0).

At GD 0, pregnant rats were housed individually in plastic cages and randomly divided into four groups. A control group of animals received tap water and three experimental groups received $\mathrm{Cd}\left(50 \mathrm{mg} / \mathrm{L} \mathrm{Cd}\right.$ as $\left.\mathrm{CdCl}_{2}\right), \mathrm{Zn}(60$ $\mathrm{mg} / \mathrm{L} \mathrm{Zn}$ as $\left.\mathrm{ZnCl}_{2}\right)$ or $\mathrm{Cd}+\mathrm{Zn}(50 \mathrm{mg} / \mathrm{L} \mathrm{Cd}+60 \mathrm{mg} / \mathrm{L} \mathrm{Zn})$ in their drinking water during gestation. $\mathrm{Cd}$ and $\mathrm{Zn}$ doses and manner of administration were chosen on the basis of our previous study (Chemek et al., 2015) and of available literature data (Brzoska et al., 2011).

\section{Sample collection and cartilage and bone staining:-}

On the 20th day of pregnancy, all animals were anaesthetized by ether inhalation; uteruses with the fetuses and placentas were removed by transversal abdominal incision, and dissected carefully. All the fetuses were weighed using a scale with $1 / 100 \mathrm{~g}$ sensibility. Litter was sacrificed by ether, totally eviscerated and skinned, then fixed in toto in ethanol 95\% for double staining with Alcian blue and Alizarin red to identify skeletal anomalies.

Embryos were skinned, eviscerated, and fixed in ethanol 95\% to dehydrate. The embryos were then transferred in acetone for 1 day to remove fat. The alcian blue/alizarin red staining was performed using a solution, as described previously (McLeod, 1980) containing $5 \mathrm{ml}$ 0.3\% alcian blue 8GX (Sigma) dissolved in 70\% ethanol, $5 \mathrm{ml} \mathrm{0.1 \%}$ Alizerin red S (Fluka) dissolved in $95 \%$ ethanol, $5 \mathrm{ml}$ glacial acetic acid,and $85 \mathrm{ml} 70 \%$ ethanol in $37^{\circ} \mathrm{C}$ incubator for 3 days. Specimens were then transferred in 1\% KOH (Sigma) for 1-2 days until skeletons are clearly visible through the surrounding skin. Then they were transferred in successive baths of $20 \%$ glycerin (Sigma) containing $1 \% \mathrm{KOH}$, and finally store in $100 \%$ glycerin. Each specimen was examined with the aid of a stereomicroscope (ZEISS).Ossification was noted as being either incomplete, low or absent.

\section{Statistical analysis:-}

Frequency data related to skeletal abnormalities were analyzed with chi-square test. Data are given as means \pm SD and values were considered statistically significant when $\mathrm{p}<0.05$.

\section{Results:-}

Body Weight and Femur Weight:-

As shown in Table 1, exposure to Cd did not affected body weights (BW) measured in GD20 fetuses, but significantly decreased $(\mathrm{p}<0.05)$ femur weight when compared to the control animals. The supplement of $\mathrm{Zn}$ has 
not recovered femur weight loss noted following exposure to $\mathrm{Cd}$. The relative femur weight (femur weight/body weight) did not show significant difference between the four groups.

Table 1:- Body weight and relative femur of rat fetuses at the $20^{\text {th }}$ day of gestation from mothers treated with cadmium (Cd) and/or zinc ( $\mathrm{Zn}$ ) during gestation.

\begin{tabular}{|c|c|c|c|c|}
\hline Finding & Control (C) & Cd & Zn & Cd+Zn \\
\hline Body weight (g) (BW) & $3,260 \pm 0,533$ & $2,991 \pm 0,41$ & $3,383 \pm 0,341$ & $3,089 \pm 0,377$ \\
\hline Femur weight (g) (FW) & $0,067 \pm 0,015$ & $0,056 \pm 0,02^{\mathrm{a}}$ & $0,067 \pm 0,022$ & $0,057 \pm 0,015^{\mathrm{a}}$ \\
\hline $\begin{array}{c}\text { Relative femur weight (\% } \\
\text { FW/BW) }\end{array}$ & $2,104 \pm 0,489$ & $1,891 \pm 0,578$ & $2,011 \pm 0,698$ & $1,872 \pm 0,491$ \\
\hline
\end{tabular}

Means \pm SE from six samples in each groups

a: $\mathrm{p}<0.01$ : significance from $\mathrm{C}$

\section{Skeletal anomalies:-}

Numerous skeletal defects were documented during examination of the stained fetal specimens. The identified malformations were localized at the axial skeleton level in different regions (skull, thoracic region, lumbar region and phalange), the highest incidence occurred after exposure to $\mathrm{Cd}$. The degree of ossification of each bone was also assessed during skeletal examination of the fetuses

\section{Craniofacial bones:-}

A significant reduction, on the degree of ossification, due to Cd exposure was observed at inter-parietal region of fetal craniofacial bone (Fig. 1). Partial ossification at three areas (parietal, frontal and squamosal bone) was also seen frequently (55\%) than controls and vs $19 \%$ for $\mathrm{Zn}$ group. After Zn supply the degree of ossification were significantly increased compared to Cd (Fig. 5a).
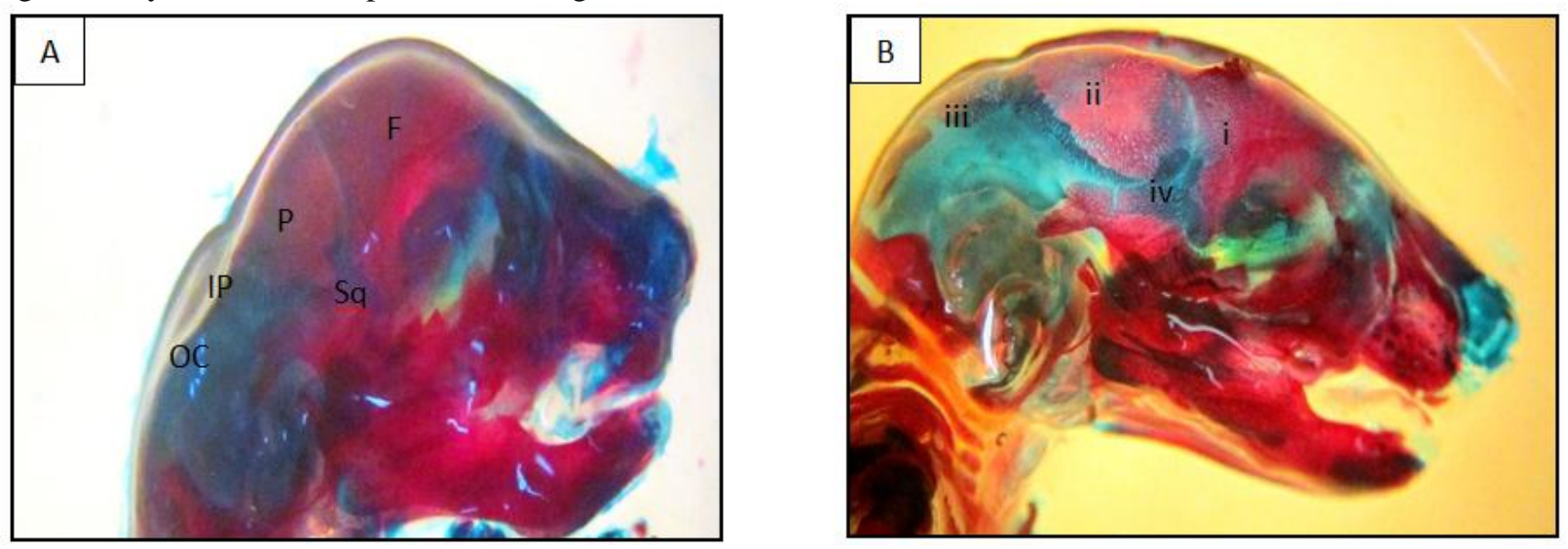

Fig1: Lateral view of the 20- days-old fetuses showing the craniofacial bones. It showed complete ossification of frontal (F), parietal (P), inter-parietal (IP), occipital (OC) and squamosal bones (Sq) in control group fetuses (A). There is partial ossification of frontal (i) and parietal (ii) bones, with reduced ossification of inter-parietal (iii) and squamosal bone (iv) inCd and/or $\mathrm{Zn}$ treated groups (B).

Ribs:-

Rib defects consist in a clear discontinuity at the level of 9 and 13 rib in animals treated with Cd compared to control (Fig. 2). Detachment and shortening ribs were also documented. Although, in Zn supplement group, only a shortening rib was identified comparing to $\mathrm{Cd}$ and control group (Fig. 5 b). 

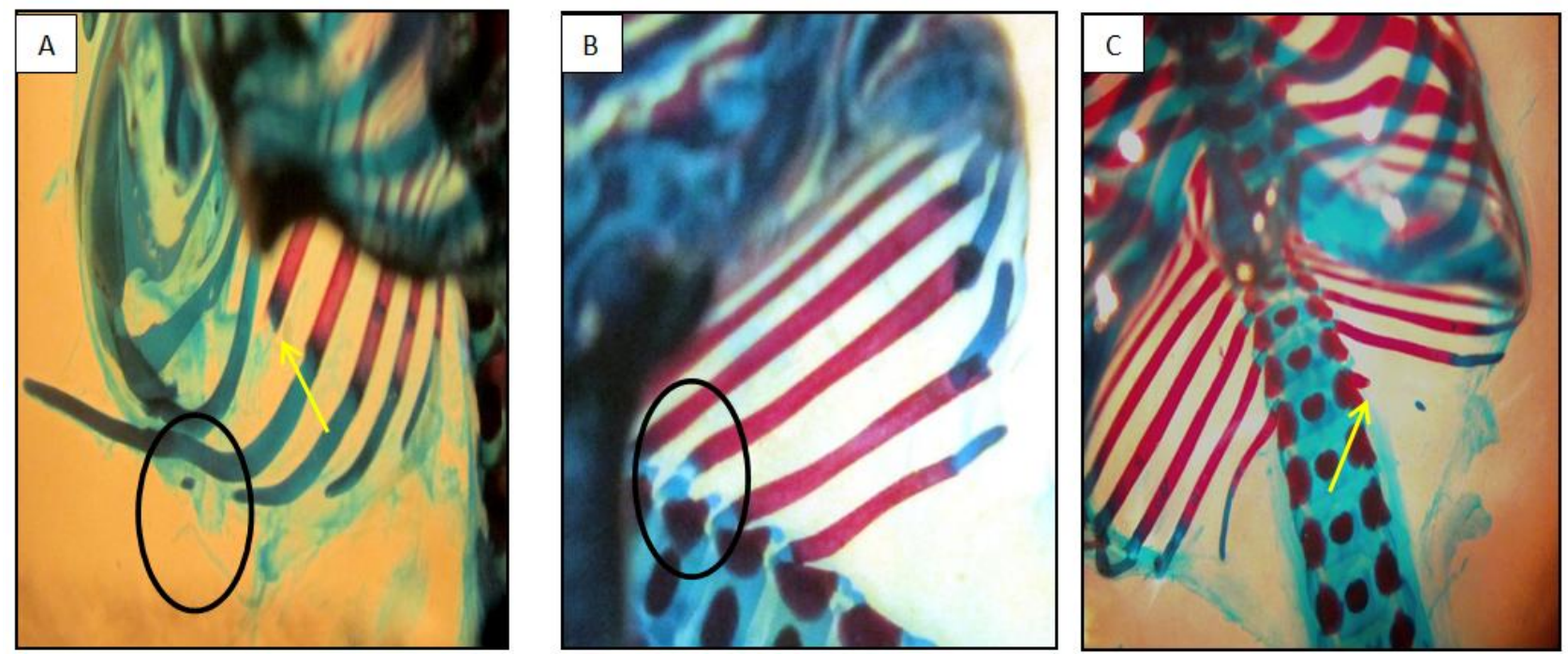

Fig 2:- Lateral view of a discontinuity and detachment of thoracic rib (A and B) and ventral view of short thoracic rib (C) of the 20- days-old fetustreated with $\mathrm{Cd}$ and/or $\mathrm{Zn}$ groups.

\section{Thoracic and lumbar vertebrae:-}

Irregularly shaped of ossified centers was identified in fetuses treated by $\mathrm{Cd}$ at the level of 10, 11, 12 and $13^{\text {th }}$ thoracic vertebrae and from the 3 rd to 6 the lumbar vertebrae. The shape was changed from the normal shape as seen in control group to a dumbbell shape (Fig. 3). In Zn supplement group, the incidence of this anomaly has significantly decreased compared to Cd group (Fig. 5 c).
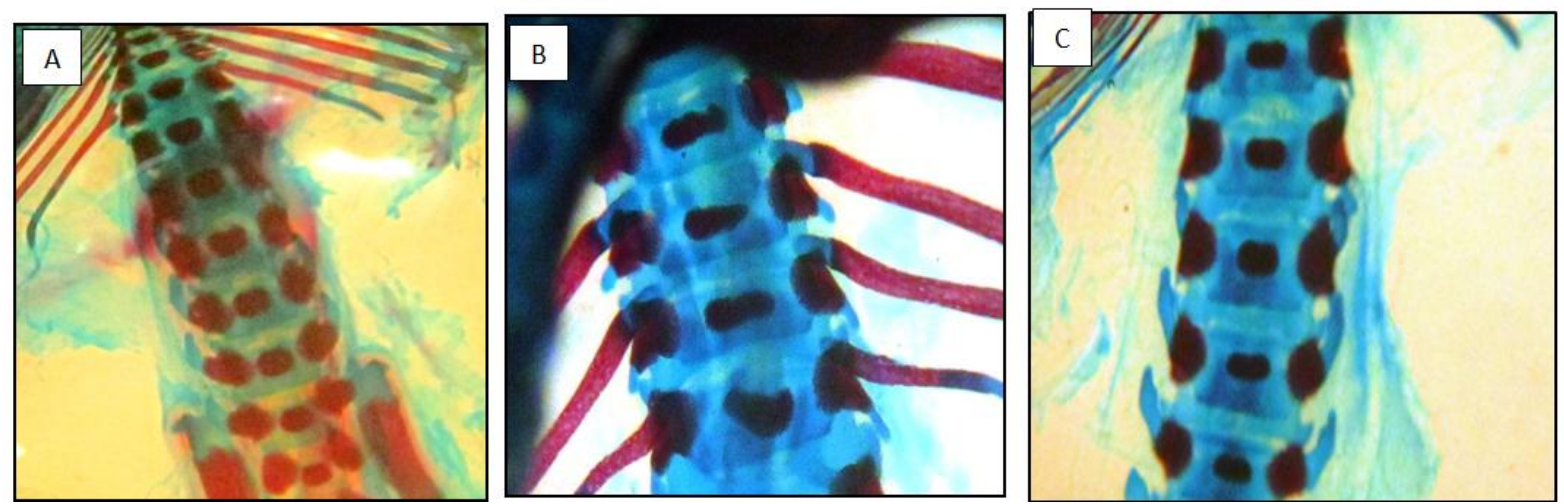

Fig 3:- Ventral view of the 20- days-old fetuses showing the vertebrae change. It showed normal ossification of the ossified centers in control group fetuses (A). Dumbbell shape of ossified centers of thoracic vertebrae (B) and lumbar vertebrae $(\mathrm{K})$ in $\mathrm{Cd}$ and/or $\mathrm{Zn}$ treated groups.

\section{Phalanx:-}

A lack of ossification at proximal phalanx of 5th finger was observed in all Cd group (Fig. 4), whereas a reduced ossification was observed in most fetuses treated with $\mathrm{Cd}$ and $\mathrm{Zn}$ simultaneously compared to $\mathrm{Cd}$ group and control (Fig. $6 \mathrm{~d}$ and e). 

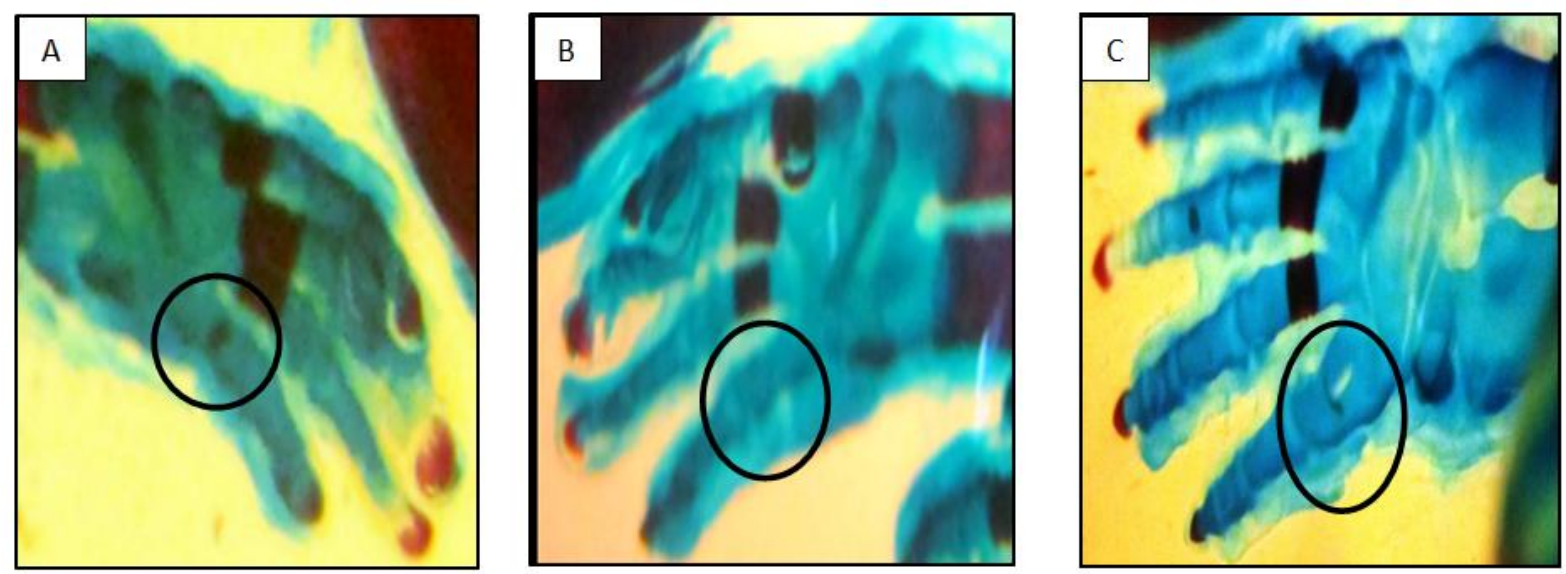

Fig 4:- Normal ossification at proximal phalanx of the fifth finger (A) of 20- days-old fetuses, lack of ossification in Cd treated group (B) and reduced ossification in $\mathrm{Cd}+\mathrm{Zn}$ treated group $(\mathrm{C})$.
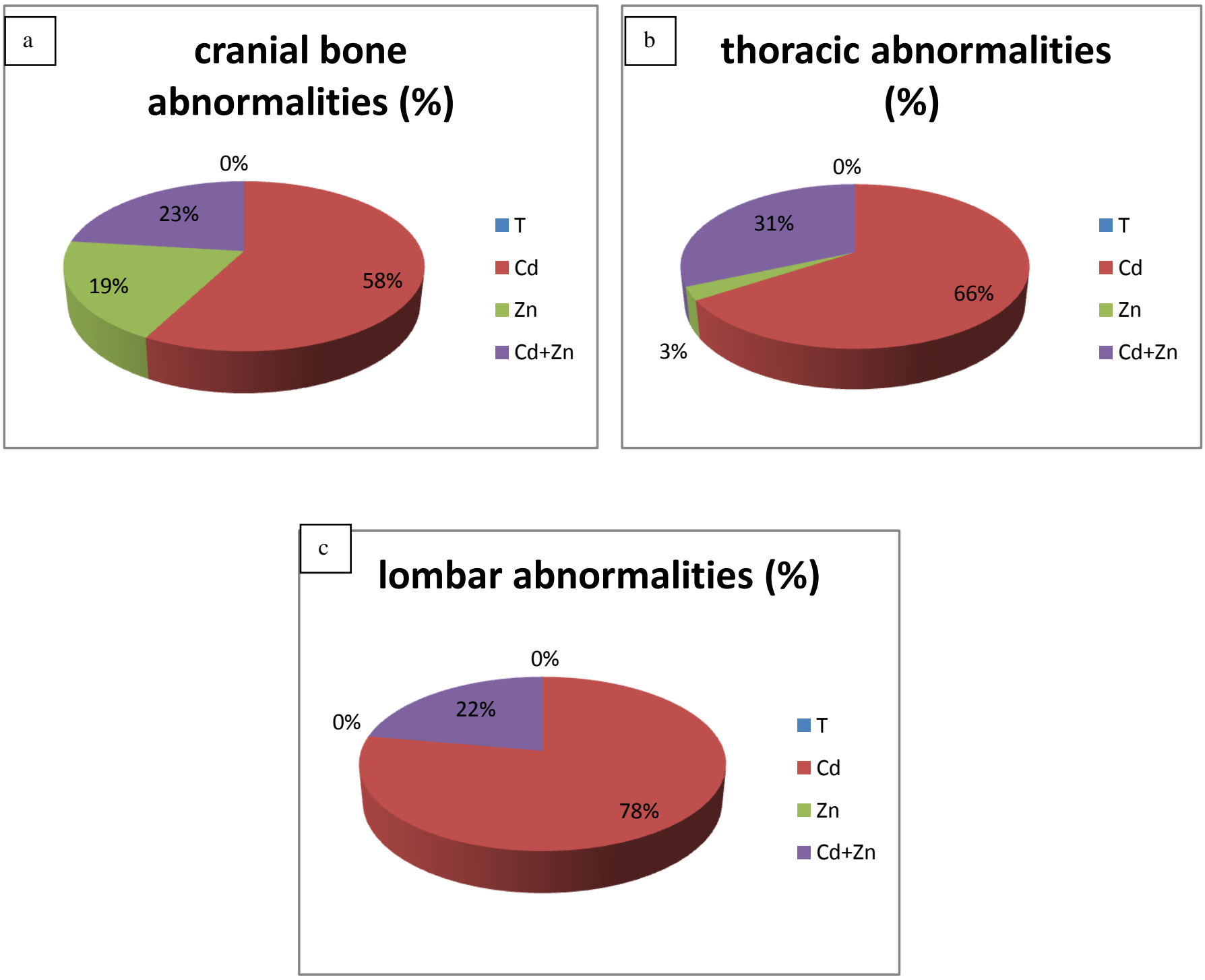

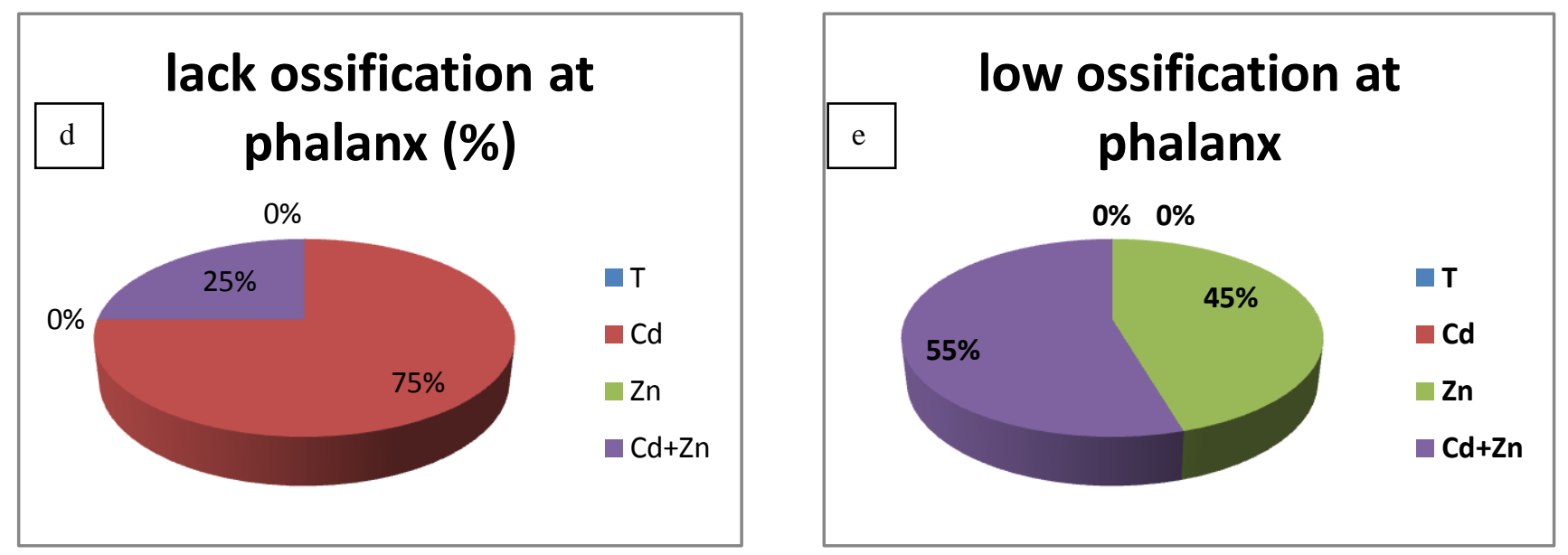

Fig 5:- Skeletal abnormalities proportions detected by double staining in fetus on GD20 following maternal treatment with $\mathrm{Cd}$ and/or $\mathrm{Zn}$.

\section{Discussion:-}

Fetal growth retardation has been shown to occur after maternal administration of a toxic compound such as lead (Salah et al., 2009) ethanol (Snow and Keiver 2007) and toluene (Gospe et al., 1994). Our data showed that maternal $\mathrm{Cd}$ intake during 20 days of pregnancy had no effect on fetal body weight, but significantly decreased femur weight. This finding was in contradiction with a previous study which reports that $\mathrm{Cd}$ exposure, from day 7 to day 16 of pregnancy, decreased fetal body weight and fetal number (Baranski et al., 1986), and partly in agreement with the result reported by Kuriwaki et al. (2004) who showed that prenatal Cd exposure from the $9^{\text {th }}$ to $19^{\text {th }}$ day of pregnancy has no effect on fetal body weight. The contrast of the results found among the different experiences may be attributed to the dose and manner of $\mathrm{Cd}$ administration or it can be explained by the timing of maternal exposure.

The fetal skeleton is a useful indicator of embryonic development and frequently reflects changes in the maternal fetal environment. In teratogenic studies, toxic effects may manifested by retardation of fetal development, such as a reduction in fetal weight. So the stage of skeletal ossification can be used in teratogenic studies in the rat to evaluate retarded fetal development (Aliverti et al 1979). Previous studies have demonstrated that the detection of skeletal abnormalities was enhanced by the technique of double staining (Rahman et al, 1996). Several abnormalities was noted in our present study by double staining besides the reduction in body weight recorded in fetus after $\mathrm{Cd}$ maternal intake. The observed anomalies were concentrated at different parts of the axial skeletal which consist of complete or incomplete ossification in the different parts of the skull (parietal interparietal and frontal). Similar results were obtained after exposure of pregnant rats to a different organophosphorus and carbamate compounds in the form of delayed and absent ossification of craniofacial especially, supraoccipital, iterperietal, presphenoid, tympanic ring and squamosal bones (Sherif et al., 2002; Haendel et al., 2004; Mohallal et al., 2005; Omar et al., 2007). At the thoracic region, a low ossification or absent at the sternum were observed besides to a detachment, a shortening or a discontinuity of ribs, with a change in the normal shape of ossified centers at the thoracic and lumbar vertebrae to a dumbbell shape. Also, a significant frequency of a lack of ossification at the proximal phalanx of the fifth finger of the hands was noted. With concomitant treatment of $\mathrm{Zn}$ and $\mathrm{Cd}$ we assisted to a decrease in anomalies frequency compared to fetus from $\mathrm{Cd}$ exposed mothers and most of anomalies observed were a low ossification in sternum segments and phalanx of the 5th finger and a shortening rib was identified. Fadel et al. (2012) noted, after topiramate administration to pregnant rats throughout day 6 to 19 of gestation, a reduction in fetal weight accompanied by a parallel decrease in the number of complete ossified vertebral centers. Weis et al. (2007) observed a decrease in the degree of ossification in axial skeletal accompanied by a reduction in the fetal weight in all groups treated with diphenyl diselenide from days 6 to 15 of pregnancy. These findings reveal a relation between morphological alterations and growth retardation. Malformations detected in some skeletal elements in our study may be due to the cartilage process which is defective caused by the administration of Cd in early stage of fetal development inducing abnormalities during endochondral ossification. 
In addition, the observed protective effect of $\mathrm{Zn}$ in our study highlights the importance of this essential element in the normal development of the fetal skeleton. $\mathrm{Zn}$ is an essential nutrient for life required for many aspects of fetal growth and plays important roles in both prenatal and postnatal bone development. In fact, studies examining effects of $\mathrm{Zn}$ deficiency in animal models have shown that mild to severe $\mathrm{Zn}$ deficiency disturbs skeletal growth and maturation (Eberle et al., 1999; Wang et al., 2002). Animals fed on Zn-deficient diets have impairment in growth plate chondrocyte proliferation (Rossi et al., 2001; Wang et al., 2002) and bone mass (Eberle et al., 1999). Bone formation in Zn-deficient animals is also characterized by retarded growth plate activity and is associated with reduced cancellous and trabecular volume (Oner et al., 1984; Rossi et al., 2001).

Our study is the first data highlighting the interactions between $\mathrm{Cd}$ and $\mathrm{Zn}$ in fetal skeleton development. The obtained results imply that $\mathrm{Cd}$ exposure during gestation has adverse effect on prenatal skeleton formation. The toxics effects of $\mathrm{Cd}$ are, partly, restored by $\mathrm{Zn}$ supplementation. Further studies are needed to reveal the mechanisms of action by which $\mathrm{Cd}$ increase skeletal abnormalities as well as to understand the mechanism involved in the protective effect of $\mathrm{Zn}$ against $\mathrm{Cd}$ toxicity during gestation.

1. Aliverti, V., Bonanomi, L., Giavini, E., Leone, V. G., Mariani, L., 1979. The extent of fetal ossification as an index of delayed development in teratogenic studies on the rat. Teratology. 20, 237-242.

2. Baranski, B., Stetkiewicz, I., Trzcinka-Ochocka, M., Sitarek, K., Szymczak, W., 1982. Teratogenicity, fetal toxicity and tissue concentration of cadmium administered to female rats during organogenesis. J. Appl. Toxicol. 2 (5), 255- 259.

3. Brzóska, M.M., Rogalska, J., Galazyn-Sidorczuk, M., Jurczuk, M., Roszczenko, A., KulikowskaKarpińska, E., Moniuszko-Jakoniuk, J., 2007. .Effect of zinc supplementation on bone metabolism in male rats chronically exposed to cadmium. Toxicology. 237, 89-103.

4. Eberle, J., Schmidmayer, S., Erben, R.G., Stangassinger, M., Roth, H.P., 1999. Skeletal effects of zinc deficiency in growing rats. J. Trace Elem. Med. Biol. 13, 21-26.

5. Fadel, R.A., Sequeira, R.P., Abu-hijleh, M.F., Obeidet, M., Salem, A.H.A., 2012. Effect of prenatal administration of therapeutic doses of topiramate on ossification of ribs and vertebrae in rat fetuses. Rom. J. Morphol. Embryol. 53(2), 321-327.

6. Gospe, Jr., Saeed S.M., Zhou, D.B., Zeman, S.S., 1994 .The effects of high-dose toluene on embryonic development in the rat. Pediatric. Res. 36, 811-815.

7. Haendel, M.A., Tilton, F., Bailey, G.S., Tanguay, R.L., 2004. Developmental toxicity of the dithiocarbamate pesticide Sodium Metam in zebra fish. Toxicol. Sci. 18, 390-400.

8. Holt, D., Webb, M., 1987. Teratogenicity of ionic cadmium in the Wistar rat. Arch. Toxicol. 59 (6), $443-447$.

9. Itokawa, Y., Nishino, K., Takashima, M., Nakata, T., Kaito, H., Okamoto, E., Daijo, K., Kawamura, J., 1978. Renal and skeletal lesions in experimental cadmium poisoning of rats. Histology and renal function. Environ. Res. 15(2), 206-217.

10. Kippler, M., Waheedu, l., Hoque, A.M., Raqib, R., Öhrvik, H., Ekström, E.V., Vahter, M., 2010. Accumulation of cadmium in human placenta interacts with the transport of micronutrients to the fetus. Toxicol. Lett. 192 (2), 162-168.

11. Kuriwaki, J., Nishijo, M., Honda, R., Tawara, K., Nakagawa, H., Hori, E., Nishijo, H., 2005. Effects of cadmium exposure during pregnancy on trace elements in fetal rat liver and kidney. Toxicol. Lett. 156, 369376.

12. McLeod, M.J., 1980. Differential staining of cartilage and bone in whole mouse fetuses by alcian blue and alizarin red S. Birth. Def. Res. part A. 22(3), 299-301.

13. Mohallal, M.E., Elokda, M.O., Hefny, H.A., Ebied, H.M., 2005. Teratogenic effect of the carbamate insecticide, methomyl, on pregnant albino mice and their offsprings. J. Egypt. Ger. Soc. Zool. 48, 83-112.

14. Nakamura, Y., Ohba, K., Suzuki, K., Ohta, H., 2012. Health effects of low-level cadmium intake and the role of metallothionein on cadmium transport from mother rats to fetus. J. Toxicol. Sci. 37 (1), 149-156.

15. Nishi, Y., 1996. Zinc and growth. J. Amer. Coll. Nutr. 15, 340-344.

16. Okano, T., 1996. Effects of essential trace elements on bone turnover in relation to the osteoporosis. Nipp. Rins. 54, 148-154.

17. Om, A.S., Chung, K.W., Chung, H.S., 2002. Effect of cadmium accumulation on renal tissues in broilers. Bull. Environ. Contam.Toxicol. 68(2), 297-301.

18. Omar, M.M.,. Abdel Rahman, G.M., Youssef, H.A.H., Fadel, R.A.R., Heider, E.A., 2007. Craniofacial ossification in rat fetuses following prenatal exposure to dimethoate and carbosulfan insecticides. Suez Canal Univ. Med. J. 10, 29-34. 
19. Oner, G., Bhaumick, B., Bala, R.M., 1984. Effect of zinc deficiency on serum somatomedin levels and skeletal growth in young rats. Endocrinology. 114, 1860-1863.

20. Rahman, M.E., Ishikawa, H., Watanabe, Y., Endo, A. 1996. Carpal and tarsal bone development is highly sensitive to three antiproliferative teratogens in mice. Reprod. Toxicol. 10 (6), 485-489.

21. Rossi, L., Migliaccio, S., Corsi, A., Marzia, M., Bianco, P., Teti, A., 2001. Reduced growth and skeletal changes in zinc-deficient growing rats are due to impaired growth plate activity and inanition. J. Nutr. 13, 1142-1146.

22. Saleh, H.A., El-Aziz, G.A., El-Fark, M.M., El-Gohary, M., 2009. Effect of Maternal Lead Exposure on Craniofacial Ossification in Rat Fetuses and the Role of Antioxidant Therapy. Anat. Histol. Embryol. 38, 392399.

23. Samarawickrama, G.P., Webb, M., 1979. Acute effects of cadmium on the pregnant rat and embryo-fetal development. Environ Health Perspect. 28, 245-249.

24. Snow, M.E., Keiver, K., 2007. Prenatal ethanol exposure disrupts the histological stages of fetal bone development. Bone. 41, 181-187.

25. Sorell, T.L., Graziano, J.H., 1990. Effect of oral cadmium exposure during pregnancy on maternal and fetal zinc metabolism in the rat. Toxicol. Appl. Pharmacol. 102, 537-545.

26. Suzuki, K.T., Tamagawa, H., Takahashi, K., Shimojo, N., 1990. Pregnancy-induced mobilization of copper and zinc bound to renal metallothionein in cadmium-loaded rats. Toxicology. 60, 199-210.

27. Tang, Z., Nandan, S., Abdul Khadeer, M., Bai, G., Franklin, R.B., Gupta, A., 2006. Overexpression of the ZIP1 zinc transporter induces an osteogenic phenotype in mesenchymal stem cells. Bone. 38(2), 181-198.

28. Thompson, J., Bannigan, J., 2008. Cadmium: Toxic effects on the reproductive system and the embryo. Reprod. Toxicol. 25, 304-315.

29. Wang, X., Fosmire, G.J., Gay, C.V., Leach, R.M., 2002. Short-term zinc deficiency inhibits chondrocyte proliferation and induces cell apoptosis in the epiphyseal growth plate of young chickens. J. Nutr. 132, 665673.

30. Weis, S.N., Favero, A.M., Stangherlin, E.C., Manarin, F.G., Rocha, J.B.T., Nogueira, C.W., Zeni, G., 2007. Repeated administration of diphenyl diselenide to pregnant rats induces adverse effects on embryonic/fetal development. Reprod. Toxicol. 23: 175-181.

31. WHO., 1992. Cadmium. Geneva, World Health Organization (Environmental Health Criteria 134). 